\title{
FINE NEEDLE ASPIRATION CYTOLOGY AS A DIAGNOSTIC TOOL IN HEAD AND NECK LESIONS
}

Yogesh Pawde ${ }^{1}$, Samir Kathale ${ }^{2}$

\section{HOW TO CITE THIS ARTICLE:}

Yogesh Pawde, Samir Kathale. "Fine Needle Aspiration Cytology as a Diagnostic Tool in Head and Neck Lesions". Journal of Evolution of Medical and Dental Sciences 2014; Vol. 3, Issue 45, September 18;

Page: 11072-11079, DOI: $10.14260 /$ jemds/2014/3445

ABSTRACT: INTRODUCTION: Palpable masses of head and neck regions are quite common, affecting all age groups. The lumps are worrisome for both, clinicians and patients as the diagnostic spectrum ranges from innocuous inflammation to life threatening malignancies. Fine needle aspiration cytology plays a vital role in solving all this issues, and fine needle aspiration cytology is now being recognized as a rapid diagnostic technique because of its simplicity and high accuracy. AIM: This retrospective study was carried out at the Department of Pathology, BSR Hospital and diagnostic Centre Rajnandgaon (C.G.) for a period of one year from April 2013 to March 2014. The aim was to know the pattern and frequency of head and neck swelling in rural Indian population, and also to know the distribution of these lesions in relation to age and sex. RESULT: A total of 241cases of head and neck swelling were observed during this period. Age of presentation varied from 1 year to 82 years with male to female ratio of 1 to 1.23. Lymph node enlargement was the commonest cause (48.54\%), followed by thyroid lesions (23.65\%). Salivary gland lesions comprised $5.8 \%$ of all lesions. Tuberculosis/Granulomatous lymphadenitis and Non-specific lymphadenitis were the most common lesion observed constituting $22.4 \%(n=54)$ each. Other common cause of swelling in region observed were due to Colloid goiter $n=44(18.25 \%)$, Cystic lesion $n=20(8.29 \%)$ and Abscess/inflammatory lesion $n=16$ (6.63\%). CONCLUSION: During the first three decades, most of the swelling of the head and neck region was either due to Tuberculosis/Granulomatous lymphadenitis or due to Reactive lymphadenitis. Among thyroid swellings both colloid goiter and thyroditis were found to be common in females. Fine needle aspiration cytology is useful in diagnosis and differentiating Neoplastic and Non Neoplastic lesions.

KEYWORDS: FNAC, Lymph node, Thyroid, Salivary gland, Soft Tissue.

INTRODUCTION: Fine Needle Aspiration Cytology is a procedure where by small amount of tissue or cells is aspirated from a pathological lesion with the help of fine $10 \mathrm{ml}$ disposable syringe of 21 or 22 Gauge needle. Virtually any superficial organ or tissue can be sampled through this procedure. Easily targeted organs include thyroid, breast, or lymphnodes. Whereas deep organs like Lungs, liver, kidney, mediastinum, and retroperitoneum are aspirated with the guidance of ultrasound or computed tomography.

FNAC is an inexpensive, safe and quick procedure, and when performed by experienced worker is quite accurate.(1) It has contributed a great deal to transform cytology from a primarily screening tool to powerful diagnostic technique.(2) The diagnosis of head and neck swelling is a common clinical dilemma for surgeons. A large number of diseases can manifest as visible or palpable swelling in the head and neck region. Commonly presenting head and neck masses are due to Lymph node, Thyroid and salivary gland Enlargement.(3) 
Less common pathologic conditions which can give rise to swelling in this region are due to thyroglossal cyst, branchial cyst, epidermal cyst and soft tissue tumors.

The proximity of tissue of various types and wide range of neoplasm are responsible for swelling at this site, making this region interesting and challenging in fine needle aspiration cytology diagnosis. The sensitivity of Fine needle aspiration cytology for diagnosis of Lymphadenopathy averages $90 \%$ with a specificity of $95 \%$.

The high degree of diagnostic accuracy, low cost and minimally disruptive nature of procedure makes Fine needle aspiration cytology a highly desirable alternative to open biopsy for investigation of cervical Lymphadenopathy.

Many reports have documented the utility of Fine needle aspiration cytology of thyroid for separating patient into operative and non-operative groups. Published results claim a sensitivity and specificity of over $90 \%$ in evaluation of thyroid nodule. $(4,5)$

The accuracy of Fine needle aspiration cytology for diagnosis of salivary gland nodules is high with studies showing an accuracy of differentiation of benign from malignant lesion to be greater than $90 \%$. $^{(6)}$

In this study we have done the audit of FNAC of head and neck lesions which has provided us spectrum of various lesions presenting at Our Hospital and diagnostic Centre. The data has revealed that the majority of lesions were benign hence management was planned with minimal surgical intervention, thereby achieving significant reduction in cost and patient morbidity.

METHODS AND MATERIAL: This retrospective study was done in the Department of Pathology, BSR Hospital and diagnostic Centre Rajnandgaon (C.G.). A total of 241 cases who presented with head and neck swelling, during a period of April 2013 to March 2014 were selected.

Fine needle aspiration cytology was done under aseptic condition using a 23 gauge needle fitted to $10 \mathrm{ml}$ disposable syringe attached to plunger.

Written consent was taken. Smears were prepared and stained with May- Grunwald Giemsa stain (MGG), haematoxylin and eosin (Hand E) and Papnicolaou stain. The Zeihl- Neelsen stain for AFB was done in those cases, where the clinical suspicion or diagnosis was tuberculosis and in those cases, where purulent or cheesy material was aspirated.

Repeat Fine needle aspiration cytology was done in cases where the yield was inadequate in the first aspiration.

OBSERVATIONS AND RESULTS: The present study includes 241 patients who had undergone FNAC for head and neck swellings. During a period of April 2013 to March 2014. Swellings were divided into different categories depending upon underlying pathology and their relative distribution is shown in Table-1.

The most common lesions were enlarged lymph nodes due to inflammation either because of Tubercular/Granulomatous inflammation (22.4\%) or Reactive lymphadenitis $(22.4 \%)$.

Others were, malignant neoplasm/Metastasis (7.8\%), benign neoplasm (8.71\%), Non neoplastic colloid goiter (18.25\%), Sialadenitis (1.25\%), abscess (6.63\%), cystic lesions (4.56\%), Thyroiditis (2.90\%) and Hemangioma / Lymphangioma (1.25\%). 


\begin{tabular}{|c|l|c|c|}
\hline $\begin{array}{r}\text { SL. } \\
\text { No. }\end{array}$ & \multicolumn{1}{|c|}{ Diagnosis } & $\begin{array}{c}\text { Number of } \\
\text { cases }\end{array}$ & Percentage \\
\hline 1. & Tubercular/Granulomatous lymphadenitis & 54 & $22.4 \%$ \\
\hline 2. & Malignant neoplasm/Metastasis & 19 & $7.8 \%$ \\
\hline 3. & Nonspecific lymphadenitis & 54 & $22.4 \%$ \\
\hline 4. & Colloid goiter & 44 & $18.25 \%$ \\
\hline 5. & Abscess/Inflammatory lesions & 16 & $6.63 \%$ \\
\hline 6. & Cystic lesions & 20 & $8.28 \%$ \\
\hline 7. & Benign neoplasm & 21 & $8.71 \%$ \\
\hline 8. & Thyroiditis & 07 & $2.90 \%$ \\
\hline 9. & Sialadenitis & 03 & $1.25 \%$ \\
\hline 10. & Hemangioma/Lymphangioma & $\mathbf{2 4 1}$ & $1.25 \%$ \\
\hline 11. & Total & $\mathbf{1 0 0 \%}$ \\
\hline
\end{tabular}

\section{Table 1: Result of FNAC showing relative frequencies of different lesions}

Table-2: Results of FNAC showing the relative frequencies of various Pathological conditions. There were 108 male patients (44.81\%) and 133 (55.18\%) female patients with male to female ratio of 1:1.23. Malignant neoplasm and Reactive lymphadenitis were common in male patients while thyroid lesions and Tubercular/Granulomatous lymphadenitis were seen more frequently in female patients as shown by Table -2 .

\begin{tabular}{|c|l|c|c|}
\hline SL. No. & Diagnosis & Male & Female \\
\hline 1. & Tubercular/Granulomatous lymphadenitis & 23 & 31 \\
\hline 2. & Malignant neoplasm/Metastasis & 12 & 07 \\
\hline 3. & Nonspecific lymphadenitis & 32 & 22 \\
\hline 4. & Colloid goiter & 08 & 36 \\
\hline 5. & Abscess/Inflammatory lesions & 12 & 04 \\
\hline 6. & Cystic lesions & 10 & 10 \\
\hline 7. & Benign neoplasm & 06 & 15 \\
\hline 8. & Thyroiditis & - & 07 \\
\hline 9. & Sialadenitis & 02 & 01 \\
\hline 10. & Hemangioma/Lymphangioma & 03 & - \\
\hline 11. & Total & $\mathbf{1 0 8}$ & $\mathbf{1 3 3}$ \\
\hline \multicolumn{4}{|c|}{ Table 2 } \\
\hline
\end{tabular}

Table-2: Sex wise distribution of cytological diagnosis Lymph node enlargement was the most frequent cause (48.54\%) of head and neck swellings, followed by thyroid pathology (23.65\%). Salivary gland comprised 5.8\% of all lesions and Miscellaneous which includes Abscess, Cysts, Soft tissue neoplasm constitute $21.99 \%$.( Table-3) 


\begin{tabular}{|c|l|c|c|}
\hline Sl. No. & \multicolumn{1}{|c|}{ Site of lesion } & Number & Percentage \\
\hline 1 & Lymph node & 117 & $48.54 \%$ \\
\hline 2. & Thyroid & 57 & $23.65 \%$ \\
\hline 3. & Salivary gland & 14 & $5.8 \%$ \\
\hline 4. & $\begin{array}{l}\text { Miscellaneous (Abscess, cyst, } \\
\text { soft tissue neoplasm etc) }\end{array}$ & 53 & $21.99 \%$ \\
\hline 5. & Total & $\mathbf{2 4 1}$ & \\
\hline
\end{tabular}

Table 3

Table-3: Site wise distribution of head and neck swellings observed Age group wise distribution is shown in Table-4. Tubercular/Granulomatous lymphadenitis (83.3\%) and Reactive lymphadenitis $(77.7 \%)$ were seen more frequently during first three decade of life while malignant neoplasms were common after third decade (78.94\%).

\begin{tabular}{|c|c|c|c|c|c|c|c|c|c|}
\hline $\begin{array}{l}\text { SL. } \\
\text { No. }\end{array}$ & Categories & $\begin{array}{l}\text { 0-10 } \\
\text { yrs }\end{array}$ & $\begin{array}{c}11-20 \\
\text { yrs }\end{array}$ & $\begin{array}{c}21-30 \\
\text { yrs }\end{array}$ & $\begin{array}{c}31-40 \\
\text { yrs }\end{array}$ & $\begin{array}{c}41-50 \\
\text { yrs }\end{array}$ & $\begin{array}{c}51-60 \\
\text { yrs }\end{array}$ & $\begin{array}{l}>60 \\
\text { yrs }\end{array}$ & Total \\
\hline 1 & $\begin{array}{l}\text { Tubercular/ Granulomatous } \\
\text { lymphadenitis }\end{array}$ & 6 & 18 & 21 & 05 & 02 & 0 & 01 & 54 \\
\hline 2 & Malignant neoplasm/Metastasis & & 3 & 1 & & 9 & 4 & 2 & 19 \\
\hline 3 & Nonspecific lymphadenitis & 24 & 5 & 13 & 7 & 5 & & & 54 \\
\hline 4 & Colloid goiter & & 4 & 13 & 14 & 10 & 1 & 2 & 44 \\
\hline 5 & Abscess/Inflammatory lesion & 2 & 2 & 4 & 6 & & 1 & 1 & 16 \\
\hline 6 & Cystic lesion & 4 & 1 & 11 & 1 & 3 & & & 20 \\
\hline 7 & Benign neoplasm & & 1 & 8 & 6 & 3 & 2 & 1 & 21 \\
\hline 8 & Thyroiditis & & 1 & 5 & 1 & & & & 7 \\
\hline 9 & Sialedenitis & & 1 & & & 1 & 1 & & 3 \\
\hline 10 & Hemangioma/Lymphangioma & 1 & 2 & & & & & & 3 \\
\hline 11 & Total & & & & & & & & 241 \\
\hline
\end{tabular}

Table-4: Age group wise distribution of cytological diagnosis among the benign neoplasm, pleomorphic adenoma and Lipoma were commonest both comprise of 9 cases (3.73\%) each. It also include cases where the cytologically possibility of warthin's tumor and Adenexal tumor was given on basis of FNA.

\begin{tabular}{|c|l|c|c|}
\hline SL. No. & \multicolumn{1}{|c|}{ Diagnosis } & Numbers & Percentage \\
\hline 1. & Pleomorphic adenoma & 9 & $3.73 \%$ \\
\hline 2. & Lipoma & 9 & $3.73 \%$ \\
\hline 3. & Warthin's tumor & 2 & $0.82 \%$ \\
\hline 4. & Adenexal tumor & 1 & $0.41 \%$ \\
\hline \multicolumn{3}{|c|}{ Table 5 } \\
\hline
\end{tabular}


Table-5: Distribution of Benign swellings of head and neck Metastatic carcinoma was the most common cause of malignant neoplasm accounting for nearly $36.84 \%$ of all malignant tumors seen. (Table-6) The next common malignant tumor observed was lymphoma (21.05\%) and papillary carcinoma (15.78\%).

\begin{tabular}{|c|l|c|c|}
\hline Sl. No. & \multicolumn{1}{|c|}{ Diagnosis } & Number & Percentage \\
\hline 1. & Metastatic carcinoma & 7 & 2.905 \\
\hline 2. & Papillary ca of thyroid & 03 & $1.25 \%$ \\
\hline 3. & Non Hodgkins lymphoma & 02 & $0.82 \%$ \\
\hline 4. & Hodgkins lymphoma & 02 & $0.82 \%$ \\
\hline 5. & Follicular neoplasm & 02 & $0.82 \%$ \\
\hline 6. & Low grade spindle cell tumor & 02 & $0.82 \%$ \\
\hline 7 & Mucoepidermoid carcinoma & 01 & 0.41 \\
\hline
\end{tabular}

Table 6: Distribution of Malignant swellings of head and neck

DISCUSSION: Most of the patients coming to our hospital belong to rural areas. They have low socioeconomic status and low education level. Many of them regularly chew tobacco and smoke and are generally ignorant about their health. So, infectious diseases and malignant conditions constitute a significant proportion of health problems among them.

Diagnostic cytology when performed by well-trained experienced individual offers a high degree of reliability and feasibility. The accuracy of cytological diagnosis depends on several factors including the experience of aspirator, sampling method, the adequacy of sample the target organ and the expertise of examiner (Cytotechnologist and cytopathologist).

The false positive diagnosis is rarely made by experienced and well trained individuals. The cytologist may make a certain false negative diagnosis. The false negative and false positive is pointers towards limitations and pitfalls in cytological interpretation in the material the observation in our study fully coordinates with the above statements.

Tubercular/granulomatous lymphadenitis and Nonspecific lymphadenitis were the most common condition in our study, accounting for $22.4 \%$ which is comparable to similar study carried out by Manjula K et al.(7) Frequency of incidence varies from $20 \%$ to $60 \%$ in different studies.(8,9,10,11). The presence of granulomas alone in the absence of necrosis was not considered diagnostic of tuberculosis and was placed under granulomatous lymphadenitis.

Tuberculosis was only reported when ZN stain for AFB were positive. Most of our patients in this category were young females and were in their first three decades of life. Lack of outdoor activity, poor nutrition and ignorance of female health in our country could be contributing factors. Malignant neoplasms were accounts for (7.8\%) cases and the commonest cause of neck swelling in patients older than 40 years. Frequency of incidence in different studies vary from $7.5 \%$ to $38.6 \%$. $8,12,13)$

Metastatic carcinoma were common with 7 cases $(2.90 \%)$ and usually presents as hard, solid mass in old age male.

Next common group in this category was lymphoma $(1.65 \%)$ which includes two cases of Hodgkin's and two of Non Hodgkin lymphoma. Three cases of papillary carcinoma and two cases Follicular neoplasm of thyroid were diagnosed. Two cases of low grade spindle cell tumor diagnosed, 
both patients were male and one case was diagnosed in young. Among salivary gland malignant lesions, one cases of mucoepidermoid carcinoma were seen.

Non neoplastic thyroid lesions i.e. goiter accounted for $18.25 \%$ of head and neck swellings. Most of the patients were female and were seen commonly during third to fifth decades of life. 7 cases (2.9\%) of Thyroiditis patients which presents as diffuse firm thyroid lesion clinically, were diagnosed by FNAC.

Cytological smears show two types of population comprising of lymphoid series cells and variable number of follicular cells with minimal colloid in the background. Hurthle cell metaplasia, giant cells and epitheloid cells were also seen. Benign neoplasm's of neck swelling accounted for 8.7\% which is comparable to study done by Manjula et al.(7)

The most common benign lesion were pleomorphic adenoma of salivary gland And Lipoma, both comprising of 9 cases each, followed by Warthin tumor. Among soft tissue tumors, Lipoma was seen more frequently than others and common site was nape of neck. Cystic lesions were found in 8.29\% of cases comparable to other studies. ${ }^{(7,9,12)}$ The common cyst was epidermal cyst (3.73\%).others were Thyroglossal cyst and Branchial cyst.

Sialadenitis comprised $1.25 \%$ of all lesions. Cytologically smears were hypocellular and show few ductal or acinar cells with inflammatory infiltrate along with fibrotic stromal fragments. Acute inflammatory process i.e. abscess comprised significant number in our study (6.63\%) and cytologically shows neutrophils and nuclear debris with fibrinoid background.

CONCLUSION: Fine Needle Aspiration Cytology is a rapid, convenient and accurate method of tissue diagnosis that can be done on an outpatient basis. FNAC offers a simple method of diagnosis of neoplastic and non-neoplastic lesions of the head and neck. The procedure is safe and free from complications and is well tolerated by the patients. There is no need of anesthesia and speedy results are obtained. So we conclude that it serves as a complementary diagnostic tool to histopathological examination.

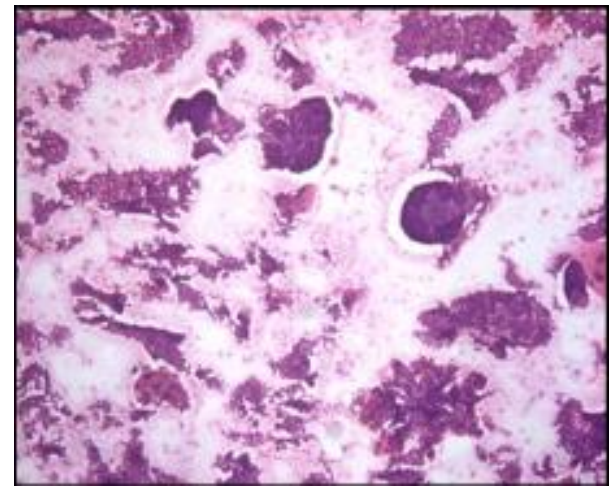

PHOTOGRAPH 1: Papillary Carcinoma Thyroid (H\&E, 10x4)

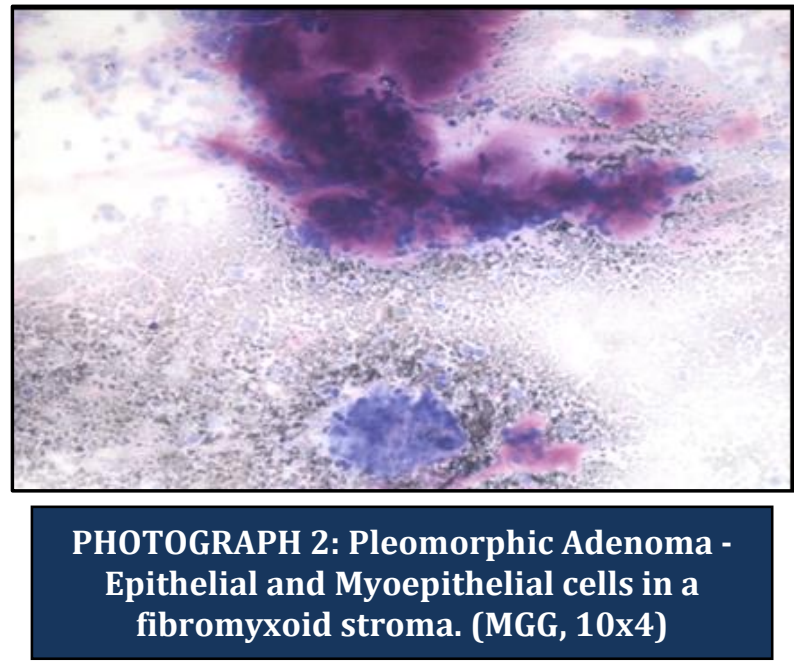




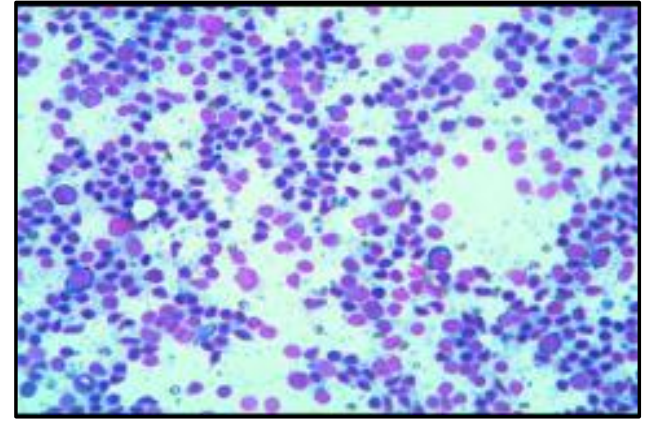

PHOTOGRAPH 3: Reactive lymph node showing polymorphous lymphoid cell population. (MGG, 10X10)

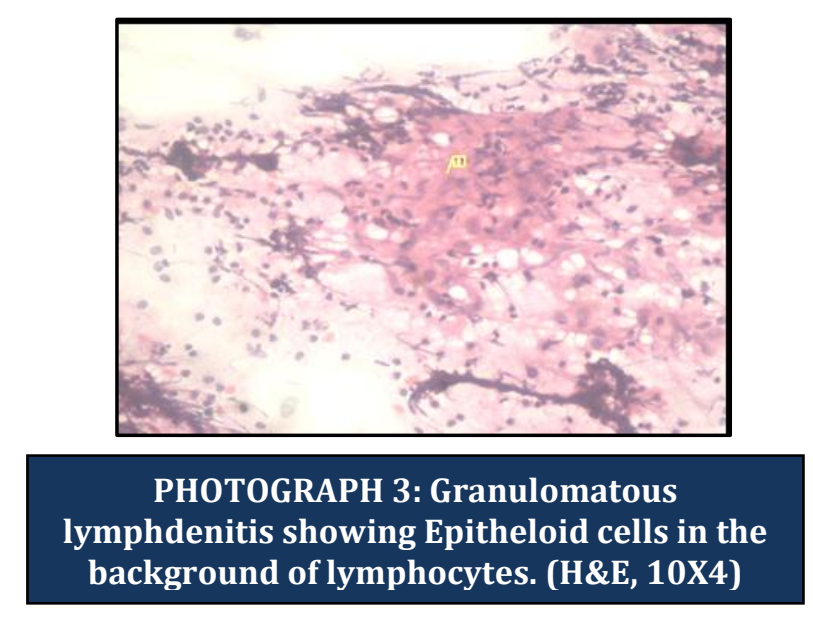

\section{REFERENCES:}

1. Frable, WJ. 1989. Needle aspiration biopsy. Past, present and future. Hum Pathol. 20: 504-517.

2. Turbat-Herrera, EA. and Knowles, K. 1999. Cytology screening or diagnostic tool? Hum Pathol 29: 1356-1366.

3. The neck. In, Das S (ed). A concise textbook of surgery, 3rd edition, Calcutta 2001; 617- 41.

4. Amrikachi M, Ramzy I, Rubenfeld S, Wheeler TM. Accuracy of Fine Needle Aspiration of Thyroid. Arch Pathol Lab Med 2001; 125: 484-488.

5. Cramer, H. Fine Needle Aspiration Cytology of Thyroid: an appraisal. Cancer Cytopathol.2000; 98: 325-329.

6. MacLeod CB, Frable WJ. Fine Needle aspiration biopsy of the salivary gland. Problem cases. Diagn Cytopathol 1993; 9: 216-225.

7. Manjula K., C.S.B.R. Prasad, Gayathri B. N., Harendra Kumar M.L. Cytomorphological study of Lateral Neck Swellings. Journal of clinical and diagnostic research.20110ct; 5: 1016-1019.

8. Ahmad T, Naeem M, Ahmad S, Samad A, Nasir A. fine needle aspiration cytology and neck swellings in the surgical outpatient. J Ayub Coll Abbottabad 2008; 20: 30-32.

9. Hag IA, Chiedozi LC, Reyees AFA, Kollur SM. Fine needle aspiration cytology of head and neck masses. Seven years' experience in a secondary care Hospital. Acta Cytol 2003; 47: 387-92.

10. Gupta RK, Naran S, Lallu S, Fauck R. The diagnostic value of fine needle aspiration Cytology in the assessment of palpable supraclavicular lymph nodes - a study of 218 Cases. Cytopathology; 8: 511-14.

11. Lawrence C, Imad AH, Shara NMNM. Study of Fine Needle Aspiration of head and Neck masses. Acta Cytol; 47: 387-92.

12. Sheahan P, Fitzgibbon JG, Leary OG, Lee G. Efficacy and pitfalls of fine needle aspiration in the diagnosis of neck masses. Surg J R Coll Surg Edinb Irel 2004; 152-7.

13. Kamal F, Niazl S, Nagi AH, Jaradi MA, Naveed IA. Fine needle Aspiration cytology (FNAC): An Experience at King Edward Medical College, Lahore. Pak J Pathol 1996; 7: 33-36. 


\section{ORIGINAL ARTICLE}

\section{AUTHORS:}

1. Yogesh Pawde

2. Samir Kathale

\section{PARTICULARS OF CONTRIBUTORS:}

1. Consulting Pathologist, Department of Pathology, BSR Hospital and Diagnostic Centre, Rajnandgaon.

2. Consulting Radiologist, Department of Radiology, BSR Hospital and Diagnostic Centre, Rajnandgaon.

\section{NAME ADDRESS EMAIL ID OF THE} CORRESPONDING AUTHOR:

Dr. Yogesh Pawde

C/O Ashok Yadav, MIG 1 House No. 533, HUDCO, Bhilai,

C. G. 490009.

Email: yogeshpawde@gmail.com

Date of Submission: 05/09/2014. Date of Peer Review: 06/09/2014. Date of Acceptance: 11/09/2014. Date of Publishing: 18/09/2014. 